
D:\Nsurg \Vol. 24, No. 1, Jan. - Mar., 2020\Nsurg-8.Doc
Fig. 1-4 Color
(A)
P. $28-32 \quad$ III

ORIGINAL ARTICLE

\title{
5 Years Mortality of Severe Traumatic Brain Injury during the Establishment of Closed System Neurocritical Care Unit in a Resource Constrained Developing Country SYED SHAHZAD HUSSAIN ${ }^{1}$, USMAN AHAMD KAMBOH ${ }^{1}$, ASIF RAZA ${ }^{1}$, HUSNAIN TAHIR ${ }^{1}$, RABIA RAZZAQ ${ }^{1}$, MOHAMMAD ASHRAF ${ }^{2}$, NAVEED ASHRAF ${ }^{1}$ \\ ${ }^{1}$ Department of Neurosurgery, Jinnah Hospital, Lahore, Pakistan. \\ ${ }^{2}$ University of Glasgow, Wolfson School of Medicine, UK.
}

DOI: $10.36552 / p j n s . v 24 i 1.416$

\begin{abstract}
Background \& Objectives: Severe traumatic brain injury is one of the leading causes of mortality and morbidity. Efficient management of severe traumatic brain injury demands a specialty driven focused intensive care. We developed our model of closed ICU driven by Neurosurgical Neurointensivist and the corollary to this commitment is a TBI patient centered Neurocritical care with the capacity and capability to deal with most of the neurological illnesses.
\end{abstract}

Materials \& Methods: A prospective study was conducted to find out the impact of the establishment of closed system of neurocritical care on 5 year mortality of severe TBI. Total 1288 patients met the inclusion criteria, which were enrolled. Tabulation was done for gender, age range, Glasgow outcome scale and mortality.

Results: It was observed that mortality reduced from $47 \%$ to $35 \%$ over a span of five years. The most common age range was 30-40 years, which is the most productive group of any population. Bed sore incidence is always on rise in any ICU. After the implementation of SOPs based management and increase in nursing staff the incidence of bedsore also showed a detrimental pattern from $35 \%$ to $19 \%$.

Conclusion: Neurocritical care unit is proven to be an integral part of any neurosurgical unit and this closed system of NCC unit provide best SOP based care with significant reduction in mortality of patients with STBI.

Keywords: Severe Traumatic Brain Injury (STBI), Standard Operating Protocols (SOP), Neurocritical Care $(N C C)$, Arterial Blood Gases (ABGs).

\section{INTRODUCTION}

Severe traumatic brain injury is one of the leading causes of mortality and morbidity .Efficient management of severe traumatic brain injury demands a specialty driven focused intensive care. The first neurosurgical ICU was set up in 1932. Spinal cord units came into existence in 1936 and 1944 and the crucial event in the history of critical care medicine was the use of electrically driven "Iron Lung" used during 1951 - 53 polio epidemic. Intensive care for severe TBI kept on evolving till 2005 when it was recognized as a specialty and now it has progressed onto multimodal Neurocritical care.

The ICU models can be characterized into open, transitional and closed and among these models it has been inferred from various studies that closed ICUs reduce morbidity and mortality. ${ }^{1,2}$

We developed our model of closed ICU driven by Neurosurgical Neurointensivist and the corollary to this commitment is a TBI patient centered neurocritical care with the capacity and capability to deal with most of the neurological illnesses.

NCC has been formalized as a specialty only relatively recently. Therefore, its dedicated units are far and few in a developing country, especially in a public sector hospital as it requires the best of everything. In year 2007, NCC based certification was developed. The main focus of NCC is to provide 
optimal care after Neurosurgical injury.

We have continuously endeavored to modernize Neurocritical care and the acquisition of state of the art facilities. It has been advocated that specialized NCC with SOP based management offer fewer chances of secondary injury with favorable outcome. ${ }^{3-6}$ Various studies have been done to compare the mortality of open and closed ICU models. Among them were studies conducted in European and African centers with the mortality rate in open ICUs were $50 \%$ and $31-26 \%$ in closed ICU settings.

So we conducted a prospective study to find out the impact of the establishment of closed system of Neurocritical care on 5 year mortality of severe TBI.

\section{MATERIALS AND METHODS}

\section{Study Design}

We conducted a prospective analysis of Neurosurgery Critical Care unit Jinnah Hospital, Lahore from January 2015 to December 2019. We included all the patients with severe traumatic brain injury admitted from emergency to the Neurocritical Care Unit.

\section{Inclusion Criteria}

Patients of both genders, age ranging from 20 to 70 years severe traumatic brain injury were included in the study.

\section{Exclusion Criteria}

Patients with polytrauma were excluded from this study.

\section{Monitoring Technique}

Neuromonitoring is essential for efficient care of NCC patients. The evaluation of Neuromonitoring plays a pivotal role in modern care of patient to reduce mortality. We started the basic techniques like CVP and vitals monitoring in 2015 and by the end of 2017 had acquired two $\mathrm{ABG}$ machines thus providing on the spot results.

And by early 2018, we had established an ICP Monitoring as a standard part of monitoring in patients of severe TBI and for other indicated patients. We have acquired advanced ventilators and the end tidal $\mathrm{PCO} 2$ is now a part of routine monitoring. The multimodal monitoring is going to be further advanced by early 2020 by the incorporation of Brain Microdialysis.

\section{RESULTS}

Total 1288 patients met the inclusion criteria and were enrolled in the study. Tabulation was done for gender, age range, Glasgow outcome scale and mortality. It was observed that mortality reduced from $47 \%$ to $35 \%$ over a span of five years.

\section{Age Incidence}

The most common age range was $30-40$ years, which is the most productive group of any population.

Bed sore incidence is always on rise in any $\mathrm{ICU}^{7}$. After the implementation of SOPs based management and an increase in nursing staff the incidence of bedsore also showed a detrimental pattern from $35 \%$ to $19 \%$.

Table 1: Neuromonitoring.

\begin{tabular}{|l|l|}
\hline Year & Up gradation \\
\hline 2015 & Vital monitoring \& central venous line \\
\hline 2016 & $\begin{array}{l}\text { Arterial line, arterial blood gases \&portable } \mathrm{x} \\
\text { ray machine }\end{array}$ \\
\hline 2017 & $\begin{array}{l}\text { 2 arterial blood gases machine \& temperature } \\
\text { probes }\end{array}$ \\
\hline 2018 & Intracranial pressure monitoring \\
\hline 2019 & Regular end tidal carbon dioxide \\
\hline
\end{tabular}

\section{Gender Distribution}

The Figure 1 shows the gender distribution among the total patients, while the figure 2 depicts the age

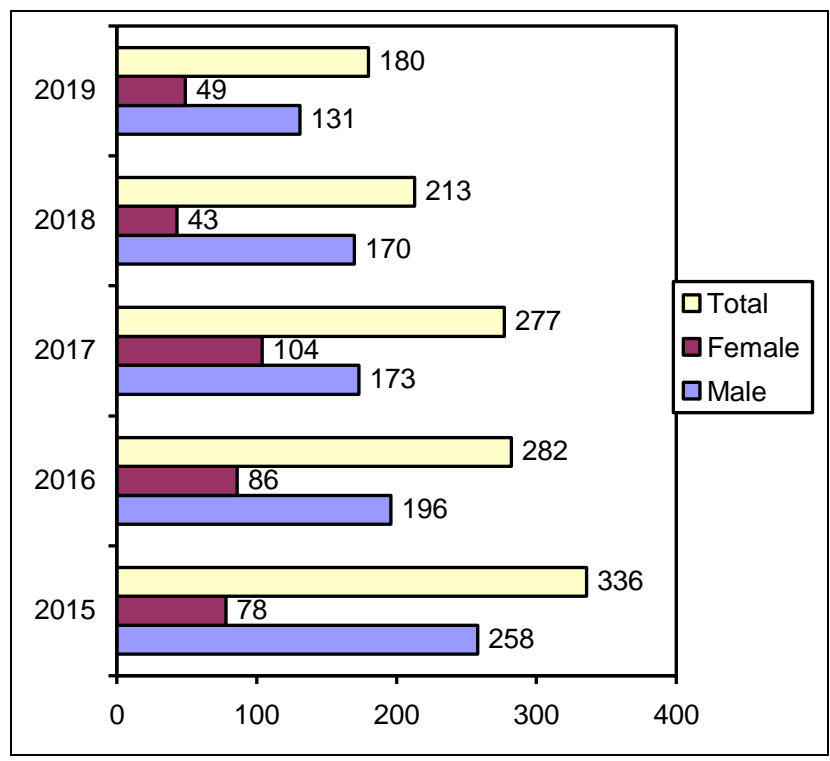

Fig. 1: Gender Distribution. 


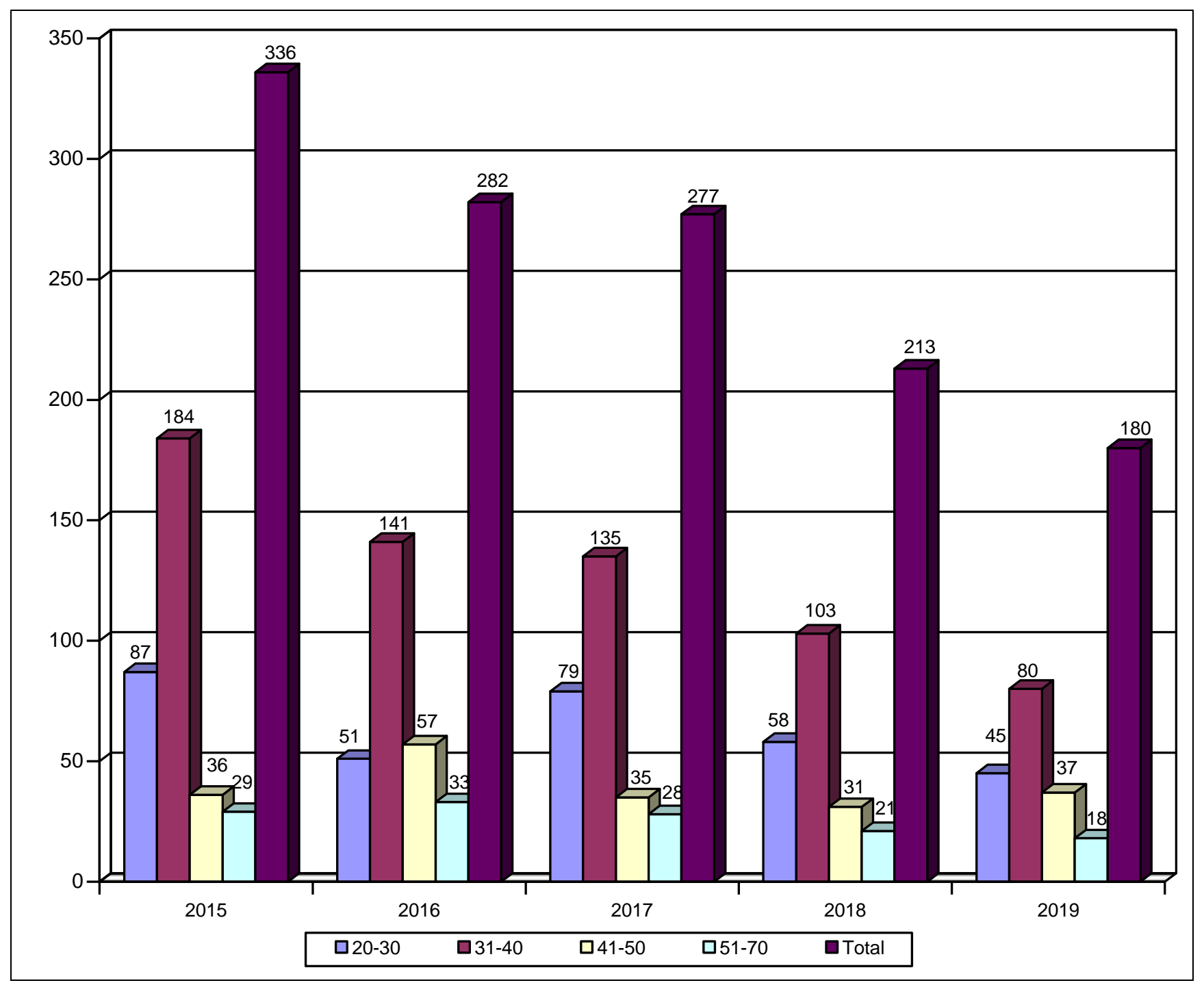

Fig. 2: Distribution of Age.

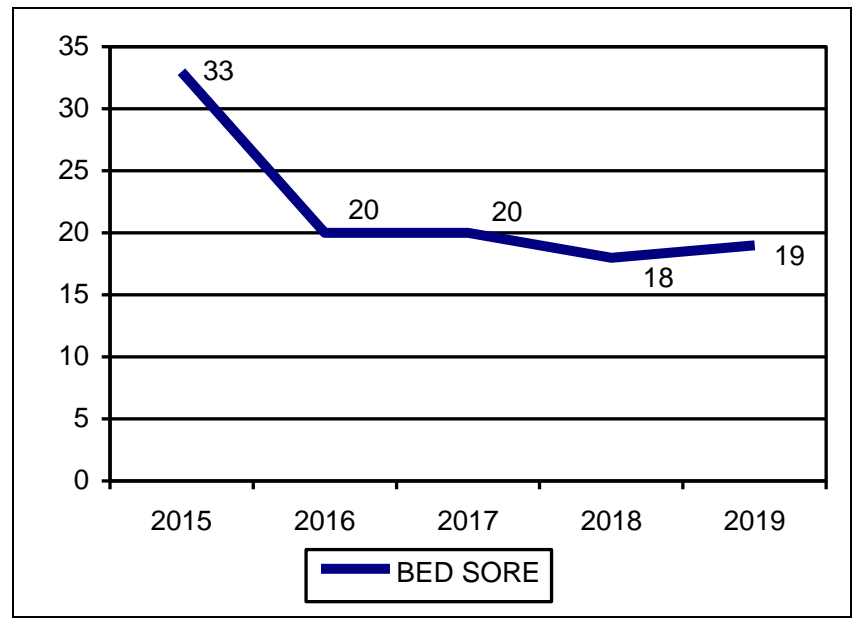

Fig. 3: Variation in Bed Sore.

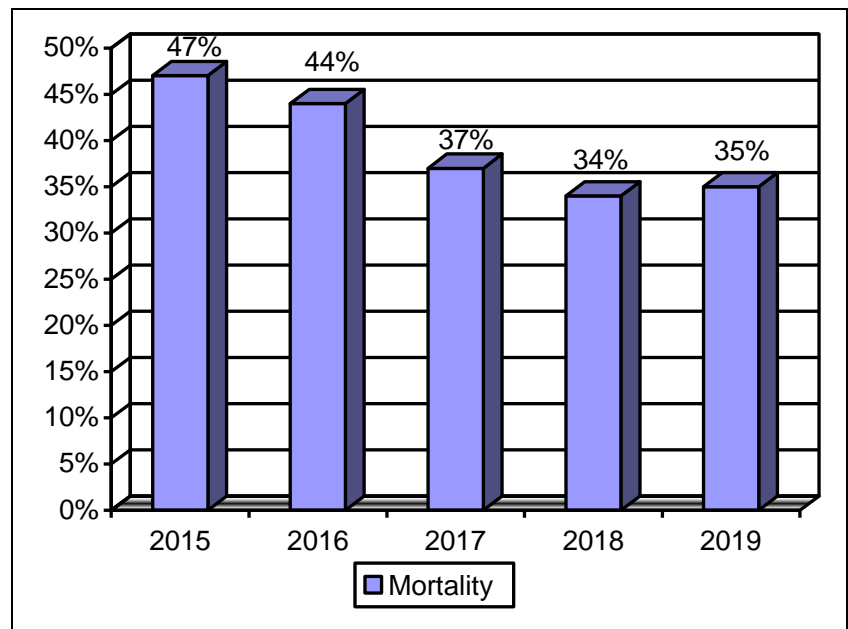

Fig. 4: Distribution of Mortality. 
range and figure 3 reveals the bed sore trend going down over the years of better care. The figure 4 showed the comparison of five year mortality.

Table 2: Glasgow Outcome Scale.

\begin{tabular}{|l|c|c|c|c|c|}
\hline GOS & $\begin{array}{c}\mathbf{2 0 1 5} \\
(\boldsymbol{\%})\end{array}$ & $\begin{array}{c}\mathbf{2 0 1 6} \\
(\boldsymbol{\%})\end{array}$ & $\begin{array}{c}\mathbf{2 0 1 7} \\
(\boldsymbol{\%})\end{array}$ & $\begin{array}{c}\mathbf{2 0 1 8} \\
(\mathbf{\%})\end{array}$ & $\begin{array}{c}\mathbf{2 0 1 9} \\
(\boldsymbol{\%})\end{array}$ \\
\hline $\begin{array}{l}\text { (Death) } \\
4\end{array}$ & 47 & 44 & 37 & 34 & 35 \\
\hline 2 & 13 & 24 & 32 & 20 & 17 \\
\hline 3 & 28 & 21 & 13 & 33 & 29 \\
\hline 4 & 9 & 11 & 17 & 7 & 19 \\
\hline 5 & 3 & 0 & 1 & 6 & 0 \\
\hline
\end{tabular}

\section{DISCUSSION}

Neurocritical care unit is born within the routine General ICU. ${ }^{8,9}$ Traumatic brain injury management is the integral part of the training of a neurosurgeon, severe traumatic brain injury always poses a major threat to life of patients in NCC unit. The efficient and SOP based management can result in remarkable improvement of outcome of STBI.

Our study showed reduction in the mortality over the years after the continuous efforts of the neurosurgical team from $47 \%$ to $35 \%$, which is still higher than the ICU all over the world, but we are hopeful the reduction in mortality will continue and over the coming years we will achieve the mortality score of international standards as we are equipped with all of the integral equipment mandatory in any standard Neurocritical unit.

The bed sore reduction to $19 \%$ is another achievement and is only possible after better nursing care and this bed sore reduction is the major contributor in mortality reduction. There is always space for better care, we continuously endeavor to improve the care of traumatic brain injury. The Glasgow outcome scale also emphasizes that over the years patients shift from NCC unit with better scores. Our results are comparable with Opondo et al., Tobi et al and Raj et al. ${ }^{4-6}$

The provision of standard equipment is mandatory for the better care in any ICU. Public sector hospitals in developing countries are always facing the obstacle of acquiring sufficient funds, but there is no alternate to the standard equipment in any ICU. The provision of $\mathrm{ABGs}$ round the clock and portable $\mathrm{X}$ ray machine facility is necessary for evaluation of adequate ventilation parameters. Neuromonitoring in patients with head injury is essential for the prevention of secondary brain insult, we acquired the intracranial pressure monitoring facility in our ICU, although it is an expensive item for the budget of the ICU of developing countries, but it can save the life of a patient who is in economically productive part of his life and his survival is not only essential economically for his family but also for the nation. The allocation of the budget should be streamlined with the function outcome of patients and for that this monitoring must be an integral part of any NCC unit. ${ }^{10}$

Neuromonitoring, paramedical staff and standard equipment is the backbone for any SOP based treatment, which results in better care.

\section{CONCLUSION}

A Neurocritical care unit is proven to be an integral part of any neurosurgical unit and this closed system of NCC unit provide best SOP based care with significant reduction in mortality of patients with STBI.

\section{REFERENCES}

1. Carson SS, Stocking C, Podsadecki T et al. Effects of organizational change in the medical intensive care unit of a teaching hospital: a comparison of 'open' and 'closed' formats. JAMA. 1996; 24-31: 276 (4): 322-8.

2. McCredie VA, Alali AS, Scales DC, et al. Impact of ICU Structure and Processes of Care on Outcomes after Severe Traumatic Brain Injury: A Multicenter Cohort Study. Critical Care Medicine, 2018; 46 (7): 11391149. DOI: $10.1097 / \mathrm{ccm} .0000000000003149$.

3. Opondo EA, Mwangombe NJM. Outcome of severe traumatic brain injury at a critical care unit: a review of 87 patients. The Annals of African Surgery, 2005; 1: 39.

4. Tobi KU, Azeez AL, Agbedia SO. Outcome of traumatic brain injury in the intensive care unit: a five year review. South African Journal of Anaesthesia and Analgesia, 2016; 22: 5, 135-139.

5. Raj R, Bendel S, Reinikainen M, et al. Traumatic brain injury patient volume and mortality in neurosurgical intensive care units: a Finnish nationwide study. Scand J Trauma Resusc Emerg Med. 2016; 24: 133. https://doi.org/10.1186/s13049-016-0320-6

6. Kuenzier M, Braun TC, Maeder MB. Mortality and outcome of severe brain Injury in Swiss Level One Trauma Centre Emerg Med (Los Angel), 2015; 5: 3-6.

7. Sayan HE, Girgin NK, Asan A.Prevalence of pressure ulcers in hospitalized adult patients in Bursa, Turkey: A 
multicentre, point prevalence study. J Eval Clin Pract. 2020. Doi: 10.1111/jep.13354.

8. M. S. Sekhon, P. Gooderham, B. Toyota, and N. Kherzi, "Implementation of neurocritical care is associated with improved outcomes in traumatic brain injury," Canadian Journal of Neurological Sciences, 2017; 44 (4): 350-357.
9. L. Knopf, I. Staff, J. Gomes, and L. McCullough, Impact of a Neurointensivist on outcomes in critically ill stroke patients, Neurocritical Care, 2012; 16 (1): 63 71.

10. Vora, T.K., Karunakaran, S., Kumar, A, et al. Intracranial pressure monitoring in diffuse brain injury - why the developing world needs it more? Acta Neurochir. 2018 160: 1291-1299.

\section{Additional Information}

Disclosures: Authors report no conflict of interest.

Ethical Review Board Approval: The study was conformed to the ethical review board requirements.

Human Subjects: Consent was obtained by all patients/participants in this study.

Conflicts of Interest: In compliance with the ICMJE uniform disclosure form, all authors declare the following:

Financial Relationships: All authors have declared that they have no financial relationships at present or within the previous three years with any organizations that might have an interest in the submitted work.

Other Relationships: All authors have declared that there are no other relationships or activities that could appear to have influenced the submitted work.

Address for Correspondence:

Syed Shahzad Hussain

Department of Neurosurgery

Jinnah Hospital

Lahore - Pakistan

Email:drshahzadns@yahoo.com

\begin{tabular}{|l|l|l|l|l|}
\hline \multicolumn{5}{|c|}{ AUTHORSHIP AND CONTRIBUTION DECLARATION } \\
\hline Sr.\# & Author's Full Name & Intellectual/Contribution to Paper in Terms of: & Signature by the \\
author(s)
\end{tabular}

Date of Submission: 20-01-2020

Date of Revision: 4-03-2020

Date of Online Publishing: 31-03-2020

Date of Print: 31-03-2020 